\title{
光機能性導波路における光モードと多重電磁波 との非線形相互作用
}

\author{
正員宮 崎 保光 (豊橋技術科学大学)
}

Non-linear Interaction of Optical Modes with Multi-

Electromagnetic Waves in Optical Functional Devices

Yasumitsu Miyazaki, Member (Toyohashi University of Technology)

High bit rate and high speed mobile radio communications using microwaves and millimeter waves are very attractive for wireless mega and giga bits LAN and video transmissions. Radio interferences due to multipropagation paths and multiple scattering by street buildings and natural structures of hills and trees are very important problems for high bit rate mobile radio communications. Real time high speed signal processing for delayed fading noises may be required. Optical signal processing using optical and radio interactions are most useful method to accomplish real time high speed signal processing. Fundamental properties and applications of optical signal processors using optical active waveguide devices are shown for high bit-rate mobile communications.

キーワード: 光尊波路, 光信号処理, 音響光学効果, 磁気光学効果, 移動通信

\section{1.はじめに}

弹性表面波 (SAW) の音響光学 (A-O) 効果およ゙び静磁表 面波 (MSSW) の磁気光学 (M-O) 効果を用いた機能性導波 路においては、電磁波と光波の相互作用が重要であり、こ れらについてはこれまでも著者らは検討を進めてきた1-5)。 最近、高速の移動通信においては、ミリ波を用いた数十 $\mathrm{M}$ 帯域の広帯域伝送に関心が持たれている。また、高速の情 報システムにおいても、リアルタイムの高速信号処理が必 要である。才なわち、電磁波の信号処理を行うために、光 波との相互作用を用いた光導波路素子が有效と考えられる。 これまで、プレーナ型の光機能素子については、検討が試 みられているが、チャンネル型の光導波路素子における非 線型相互作用に基づいた高速処理については殆ど検討がな されていない。ここでは、光機能性導波路における光モー ドと多重電磁波との相互作用についての基礎理論を示して いる。

とくに、高速無線 LANに扮いては、信号と遅延雑音と の相関処理および信号と遅延雑音を含む受信波において、 信号を識別するには実時間の高速処理が必要である。

受信信号を電気系の入力とし、光導波路の屈折率分布を 制御することにより、光モードの結合特性を変化すること

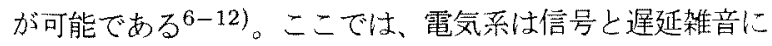
よる多重電磁波として考え、光機能性導波路において、光 波と多重電磁波との相互作用を非線形効果として論じ、時

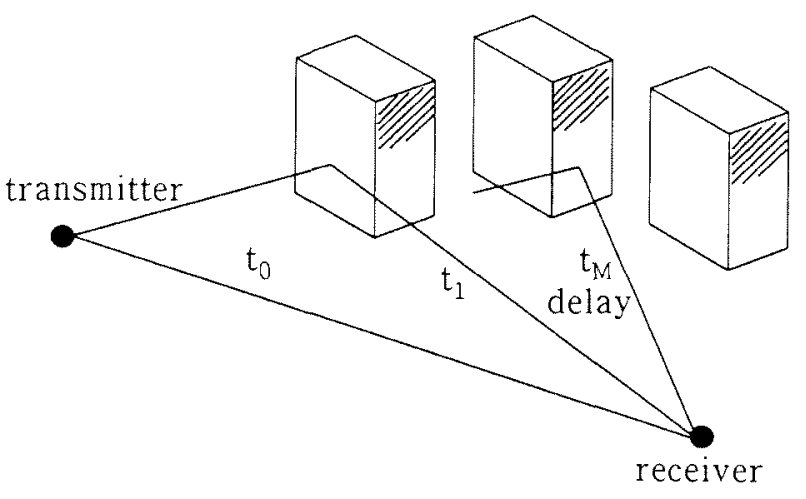

図 1 移動体通信における干渉とフェージング 遅延時間 $\Delta t=1 \mathrm{~ns}$ は距雄差 $\Delta \ell=0.3 \mathrm{~m}$ に対応 $\begin{array}{lc}1 \mu \mathrm{s} \cdots & 0.3 \mathrm{~km} \\ 0.5 \mu \mathrm{s} \cdots & 0.15 \mathrm{~km}=150 \mathrm{~m}\end{array}$

Fig. 1. Interference and fading effects in mobile communications 


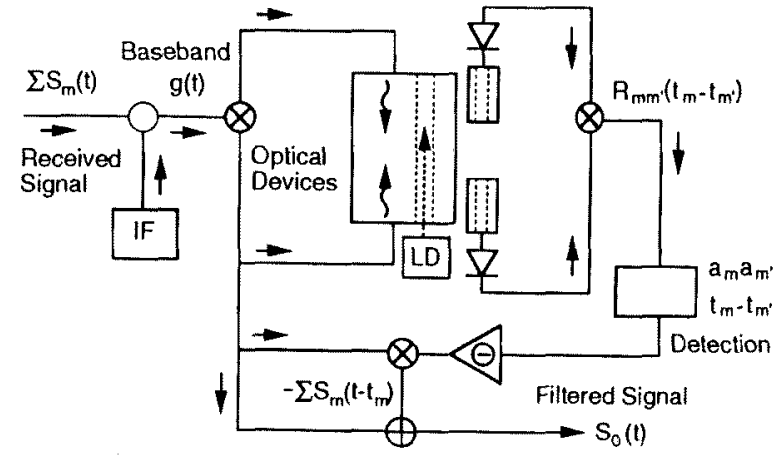

図 2 受信波の相関と光モード変換

Fig. 2. Correlation process and filtered signal

間的なダイナミック特性を考察する。とくに、時間的特性 を中心に光モード特性の非線形相互作用を明らかにする。

\section{2. 実時間信号処理}

メガおよびギガビット伝送の高速移動通信においては、 図 1 に示寸ように信号波上電磁干渉による遅延波により構 成さ狆る受信波における信号識別、フィルタリングが重要 である。ベースバンド周波数带域において、受信波信号は 1 つのパルス波形が $f_{m}(t)$ である $N$ 個のパルス列をもち、 $M$ 個の遅延波が生じるとき、受信波は

$$
g(t)=\sum_{m=0}^{M} g_{m}\left(t-t_{m}\right)
$$

$こ こ に$

$$
g_{m}\left(t-t_{m}\right)=\sum_{n=0}^{N} a_{m} f_{m}\left(t-t_{m}-n \tau_{0}\right),
$$

$\tau_{0} 、 a_{m} 、 t_{m}$ は、パルス幅、干渉強度、遅延時間である。 2 つの受信波 $g_{m}$ と $g_{m^{\prime}}$ の相関は

$$
R_{m m^{\prime}}\left(t_{m}-t_{m^{\prime}}\right)=\int_{-\infty}^{\infty} g_{m}\left(t-t_{m}\right) g_{m^{\prime}}\left(t-t_{m^{\prime}}\right) d t(3)
$$

であり、相関開数 $R_{m m^{\prime}}$ より遅延時間が評価される。

光機能性導波路において、電気系入力として、SAW あ るいは MSSW 波の2つの入力として、 $g_{m} 、 g_{m^{\prime}}$ を印加す れば、音響光学効果あるいは、MSSW の磁気光学効果によ り、光モードに関寸る、光波と無線電磁波の非線形光学効 果により、光出力として、式(3)の $R_{m m^{\prime}}$ が得られる。

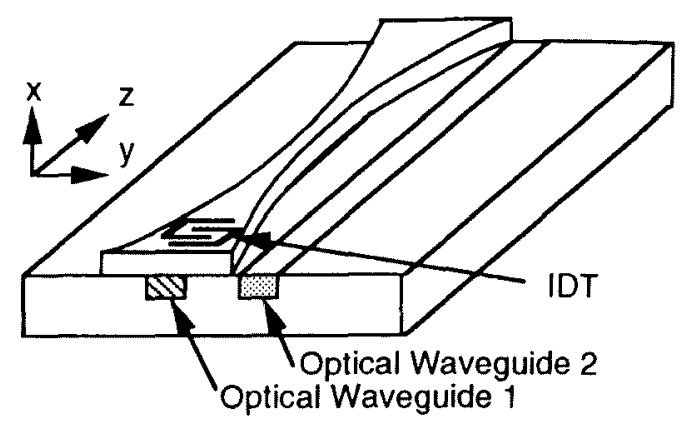

図 3 SAW の音響光学効果による光モ一ド変換

Fig. 3. Optical mode conversions due to A-O effects of SAW

図 2のように例えば、SAW あるいは MSSW のトラン デューサ電気系入力として、受信波のベースバンド電磁波 が印加される信号が、伝搬軸方向に沿って $g_{1}(t / 2-z / v)$ 、 $g_{2}(t / 2+z / v)$ のうに逆方向伝搬する場合には、A-O あ るいは MSSW 効果の光モード出力は、つぎのように示さ れる。

$$
R(t)=\int g_{1}(\tau) g_{2}(t-\tau) d \tau
$$

$こ こ に$

$$
\tau=\left(\frac{t}{2}-\frac{z}{v}\right)
$$

信号波形が時間反転対称のとき、式 (4) は式 (3) に等価と なる。式(3)にお゙いて、 $R_{m m^{\prime}}$ がピークを持つ值により遅 延時間 $t_{m}$ が与えられ、したがって遅延による干渉雑音は、 受信波から、 $t_{m}$ により求められる遅延波列を適当な重み係 数を用いて、減法することによりフィルタリング可能であ る。 $R(t)$ のフーリエ変換 $\hat{R}(\omega)$ は $g_{1}$ と $g_{2}$ のフーリエ変換、 $\hat{g}_{1}(\omega)$ と $\hat{g}_{2}(\omega)$ を用いれば

$$
\hat{R}(\omega)=\hat{g}_{1}(\omega) \hat{g}_{2}(\omega)
$$

の関係が成立する。式(6) の右辺は、受信波の 2 つ電気 系入力の周波数成分の積を示している。式 $(6)$ は、光機能 性導波路においては、2 次の光モード变換係数に対応寸る。

\section{3. 光波と SAW, MSSW との相互作用}

SAW のA-O 効果およびMSSW の M-O 効果を用いた 集積型の光導波路に执いて、光導波路は、光波亡 $\mathrm{SAW} 、$ 
MSSW との間の非線形相互作用を有寸る。これらの効果は 以下のように届折率の変化として示される。光導波素子の 例老図3、4 に示守。

SAWの A-O 効果は屈折率变化として、

$$
\Delta n_{i j}=-\frac{1}{2} \sum_{k, l} \frac{n_{i k}^{2}}{n_{i j}}\left(\sum_{\alpha, \beta} p_{k i \alpha \beta} s_{\alpha \beta}\right) n_{l j}^{2}
$$

ここに、 $n$ は屈折率、 $p$ は光弹性定数、sは歪テンソルであ る。このとき、SAW の変位ベクトル $\boldsymbol{u}$ 、電気系周波数 $\omega^{\prime}$ を 用いて、䄧電率変化は、SAW $i$ タイプに対して

$$
\begin{aligned}
& \Delta \varepsilon^{(i)}\left(\boldsymbol{r}, \omega^{\prime}\right)=\boldsymbol{p}: \boldsymbol{s}\left(\boldsymbol{r}, \omega^{\prime}\right), \\
& \boldsymbol{s}=b \boldsymbol{u}_{a}\left(\boldsymbol{r}_{\boldsymbol{i}}, z, \omega^{\prime}\right) \exp \left[-j \beta_{a}\left(z, \omega^{\prime}\right) z\right]
\end{aligned}
$$

MSSW の M-O 効果は、外部印加静磁界が $y$ 方向で、磁 化がMのとき、誘電率変化は、

$$
\begin{aligned}
& n_{i j}=\sqrt{\varepsilon_{i j}}, n_{i j}+\Delta n_{i j} \\
& \Delta \tilde{\varepsilon}_{p}(t)=\left[\begin{array}{ccc}
\varepsilon_{p x x}^{(1)} & j f_{p} M_{p} & -j f_{p} m_{p z} \\
-j f_{p} M_{p} & \varepsilon_{p y y}^{(1)} & j f_{p} m_{p z} \\
j f_{p} m_{p z} & -j f_{p} m_{p x} & \varepsilon_{p z z}^{(1)}
\end{array}\right]
\end{aligned}
$$

ここに、

$$
\begin{aligned}
& \Delta \tilde{\varepsilon}_{p}(t)=\left(f_{i j} m_{p}^{(i j)}\right), \\
& f_{p}=\frac{2 \sqrt{\varepsilon_{p}} \phi_{p}}{k_{0} M_{p}} \ldots \ldots
\end{aligned}
$$

$\phi_{p}$ はファラデ回転定数、電気系周波数 $\omega_{M}$ の高周波磁化 $\boldsymbol{m}_{p}$ は

$$
\begin{aligned}
4 \pi \boldsymbol{m}_{p} & =4 \pi m_{p x} \boldsymbol{i}_{x}+4 \pi m_{p z} \boldsymbol{i}_{z} \\
& =-\mu_{0}\left(\tilde{\mu}_{r p}-\tilde{I}\right) \cdot \nabla \Psi_{p} \ldots \ldots \ldots \ldots \\
m_{p i} & =M_{p}^{(i)} \sin \theta_{m}^{(i)} \exp \left[j \omega_{M} t-j \beta_{M S} z\right]
\end{aligned}
$$

世 中 MSSWの静磁界ポテンシャルである。

SAW の A-O 効果、MSSW の M-O 効果をもつチャンネ ル型光導波路において、コア部分における屈折率分布は、 多重周波数による光効果により変化するが、一般には次の ように示される。

$$
\Delta \varepsilon=\sum_{i} \Delta \varepsilon^{(i)}(\boldsymbol{r}, t), \Delta \hat{\varepsilon}=\sum_{i} \Delta \hat{\varepsilon}^{(i)}\left(r, \omega^{\prime}\right)
$$

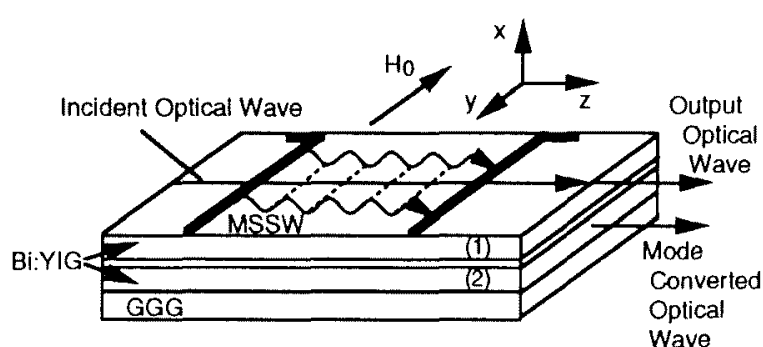

(a) Optical device with MSSW

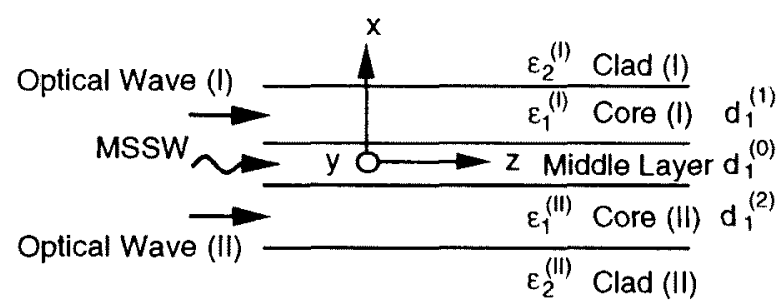

(b) Mode conversion by MSSW

図 4 MSSW の磁気光学效果による光モード変換

Fig. 4. Optical mode conversions due to M-O effects of MSSW

ここに、

$$
\begin{aligned}
& \Delta \hat{\varepsilon}=\int_{-\infty}^{\infty} \Delta \varepsilon(r, t) \exp \left[-j \omega^{\prime} t\right] d t \\
& \Delta \varepsilon=\frac{1}{2 \pi} \int_{0}^{\infty} \Delta \hat{\varepsilon} \exp \left[j \omega^{\prime} t\right] d \omega^{\prime}
\end{aligned}
$$

光機能性導波路における光モードの電界は、

$$
\begin{aligned}
& \hat{\boldsymbol{E}}(\boldsymbol{r}, \omega)=\int_{-\infty}^{\infty} \boldsymbol{E}(\boldsymbol{r}, t) \exp [-j \omega t] d t \\
& \boldsymbol{E}(\boldsymbol{r}, t)=\frac{1}{2 \pi} \int_{0}^{\infty} \hat{\boldsymbol{E}}(\boldsymbol{r}, \omega) \exp [j \omega t] d \omega
\end{aligned}
$$




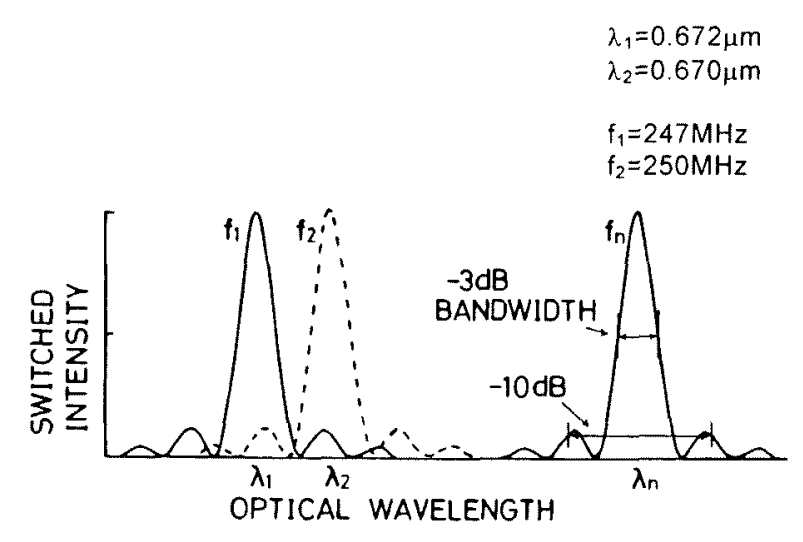

(a) Optical filtering by SAW

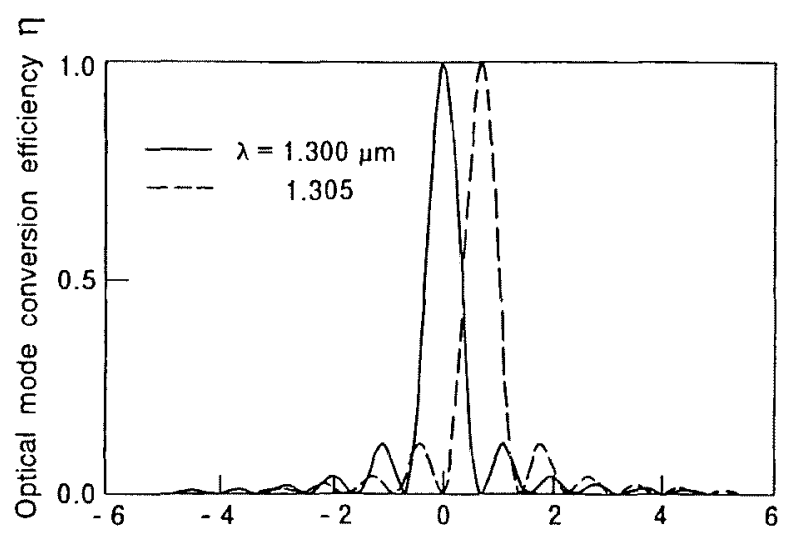

Frequency deviation from center [ $\mathrm{MHz}$ ]

(b) Optical filtering by MSSW

図 5 SAW、MSSW と光波の相互作用による光 波長の光フイルタリング特性

Fig. 5. Characteristics of optical wavelength filtering by interaction with SAW and MSSW

$$
\hat{\boldsymbol{E}}(\boldsymbol{r}, \omega)=\sum_{i} \hat{\boldsymbol{E}}^{(i)}(\boldsymbol{r}, \omega)
$$

非線形光効果により、屈折率分布制御が行われるチャンネ 儿型光導波路においては、電界は次の波動方程式を满たす。

$$
\nabla \times \nabla \times \hat{\boldsymbol{E}}(\boldsymbol{r}, \omega)-\mu \varepsilon \omega^{2} \hat{\boldsymbol{E}}(\boldsymbol{r}, \omega)=
$$

$$
\begin{aligned}
& \mu\left[\int\left(-\omega^{\prime 2}\right) \Delta \hat{\varepsilon}\left(\omega^{\prime}\right) \hat{\boldsymbol{E}}\left(\omega-\omega^{\prime}\right) d \omega^{\prime}\right. \\
& +\int\left(-2 \omega^{\prime}\right)\left(\omega-\omega^{\prime}\right) \Delta \hat{\varepsilon}\left(\omega^{\prime}\right) \hat{\boldsymbol{E}}\left(\omega-\omega^{\prime}\right) d \omega^{\prime} \\
& \left.+\int\left(-\left(\omega-\omega^{\prime}\right)^{2}\right) \Delta \hat{\varepsilon}\left(\omega^{\prime}\right) \hat{\boldsymbol{E}}\left(\omega-\omega^{\prime}\right) d \omega^{\prime}\right]
\end{aligned}
$$

式(17)において、光の周波数 $\omega$ は、電気系の周波数 $\omega^{\prime}$ に比

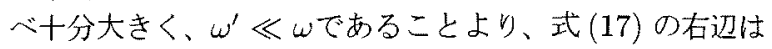
次式となる。

$$
-\int \omega^{2} \mu \Delta \varepsilon\left(\omega^{\prime}\right) \hat{\boldsymbol{E}}\left(\omega-\omega^{\prime}\right) d \omega^{\prime}
$$

\section{4. 相互作用によるモード結合}

外部からの電気采電磁界により制御される光能動性効果 を持つチャンネル光導波路の電磁界特性は、固有值 $\beta_{\alpha}$ 、固 有ベクトル関数 $\phi_{\alpha}$ 老持つGreen's dyadicにより解析され る。コア領域とクラッド領域が A-O 効果およびM-O 効果 を有寸る結合導波路において、微分演算子 $\mathcal{L}$ 、電界 $\mathcal{E}$ 、源

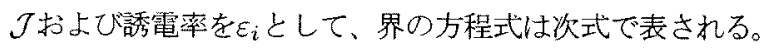

$$
\begin{aligned}
& \mathcal{L}_{i j}=(\nabla \times \nabla \times)-\omega^{2} \varepsilon_{i} \mu, \quad \mathcal{L}_{0}=\left(\begin{array}{cc}
\mathcal{L}_{11} & 0 \\
0 & \mathcal{L}_{22}
\end{array}\right) \\
& \mathcal{E}=\left(\begin{array}{c}
E_{1} \\
E_{2}
\end{array}\right), \quad \mathcal{J}=\left(\begin{array}{l}
\boldsymbol{J}_{1} \\
\boldsymbol{J}_{2}
\end{array}\right), \ldots \ldots \ldots(19)
\end{aligned}
$$

$\mathcal{G} \odot$ Green's dyadic $\Gamma$ を用いて

$$
\mathcal{L}_{\mathrm{O}} \mathcal{E}=\mathcal{J}
$$

$$
\mathcal{L}_{0}^{-1} \mathcal{J}=\mathcal{G J}=\int\left(\begin{array}{ll}
\hat{\Gamma}_{11} & \hat{\Gamma}_{12} \\
\hat{\Gamma}_{21} & \hat{\Gamma}_{22}
\end{array}\right)\left(\begin{array}{c}
J_{1} \\
J_{2}
\end{array}\right) d v(20)
$$

ここに、

$$
\begin{array}{r}
\hat{\boldsymbol{\Gamma}}_{i j}\left(\boldsymbol{r}, \boldsymbol{r}^{\prime}\right)=\sum_{\alpha} \frac{\phi_{\alpha}(\boldsymbol{r}, \omega) \phi_{\alpha}\left(\boldsymbol{r}^{\prime}, \omega\right)}{M_{\alpha}(\omega)} \\
\quad \times \exp \left[-j \beta_{\alpha}(\omega)\left|z-z^{\prime}\right|\right] \cdots \cdots \\
\int \phi_{\alpha}\left(\boldsymbol{r}_{t}, \omega\right) \phi_{\alpha^{\prime}}\left(\boldsymbol{r}_{t}, \omega\right) d^{2} \boldsymbol{r}_{t}=\delta_{\alpha \alpha^{\prime}}
\end{array}
$$

ここで、 $M_{\alpha}(\omega)$ は固有関数の正規化定数である。 Green の公式を用いて、界は次式で表される。 


$$
\begin{aligned}
& \hat{\boldsymbol{E}}_{t o t l}=\int \hat{\boldsymbol{\Gamma}}_{i j} \int \mu \omega^{2} \Delta \hat{\varepsilon}_{j}\left(\omega^{\prime}\right) \hat{\boldsymbol{E}}_{j}\left(\omega-\omega^{\prime}\right) d \omega^{\prime} d v^{\prime} \\
& \quad-\int_{S_{0}} \int_{S_{i}} n \cdot\left[\left(\nabla \times \hat{\boldsymbol{E}}_{t o t l}\right) \times \hat{\boldsymbol{\Gamma}}\right. \\
& \left.\quad+\hat{\boldsymbol{E}}_{t o t l} \times(\nabla \times \hat{\boldsymbol{T}})\right] d \boldsymbol{S}^{\prime} d \omega^{\prime} \ldots \ldots \ldots \ldots(22)
\end{aligned}
$$

一般に、光能動性効果をもつ光電磁界は、固有ベクトル 関数 $\phi_{\alpha_{i}}$ のモード振幅 $a_{\alpha_{i}}$ により示される。

$$
\begin{array}{r}
\hat{\boldsymbol{E}}_{i}\left(\boldsymbol{r}_{t}, \omega\right)=\sum_{\alpha} a_{\alpha_{i}}(z, \omega) \boldsymbol{\phi}_{\alpha_{i}}\left(\boldsymbol{r}_{t}, \omega\right) \\
\quad \times \exp \left[-j \beta_{\alpha_{i}}(\omega) z\right] \ldots \ldots \ldots \ldots
\end{array}
$$

不均質な光機能性導波路にGreen の公式を適用寸れば、式 (17)、(21)、(23) より、モード振幅幅についての結合方程式 が導かれる。すなわち、モード振幅 $a_{\alpha_{i}}$ は次式で表される。 SAW のA-O 効果の場合、

$$
\begin{aligned}
& a_{\alpha_{i}}(z, \omega)=\frac{1}{M_{\alpha}} \int d S^{\prime} \int_{z_{0}}^{z} e^{-j \beta_{\alpha_{i}}(\omega)\left(z-\left|z-z^{\prime}\right|\right)} \\
& \quad \times \phi_{\alpha_{i}}\left(\boldsymbol{r}^{\prime}, \omega\right)\left(\mu \omega^{2}\right) b \boldsymbol{p}\left(\boldsymbol{r}_{t}^{\prime}, z^{\prime}\right): u_{a}\left(\boldsymbol{r}_{t}^{\prime}, z^{\prime}\right) e^{-j \beta_{a}\left(\omega^{\prime}, z^{\prime}\right) z^{\prime}} \\
& \quad \times \sum_{\alpha^{\prime}} a_{\alpha_{i}^{\prime}}\left(z^{\prime}, \omega-\omega^{\prime}\right) \phi_{\alpha_{i}^{\prime}}\left(\boldsymbol{r}_{t}^{\prime}, \omega-\omega^{\prime}\right) \\
& \quad \times e^{-j \beta_{\alpha^{\prime}}\left(\omega-\omega^{\prime}, z^{\prime}\right)} d z^{\prime} d \omega^{\prime} \ldots \ldots \ldots \ldots \ldots(24)
\end{aligned}
$$

したがって、振幅の進行方向の変化について、

$$
\begin{aligned}
& \frac{d a_{\alpha_{i}}(z, \omega)}{d z}=\sum_{\alpha} \int a_{\alpha_{i}^{\prime}}\left(z, \omega-\omega^{\prime}\right)(-j) \\
& \times \zeta_{\alpha \alpha^{\prime}}\left(z, \omega, \omega^{\prime}, \omega-\omega^{\prime}\right) \\
& \times \exp \left[j \beta_{\alpha_{i}}(\omega) z-j \beta_{\alpha_{i}^{\prime}}\left(\omega-\omega^{\prime}\right) z-j \beta_{a}\left(\omega^{\prime}, z^{\prime}\right) z^{\prime}\right] d \omega^{\prime}
\end{aligned}
$$

ここで、モード結合係数は、たとえば、A-O 効果の場合、

$$
\begin{aligned}
& (-j) \zeta_{\alpha, \alpha^{\prime}}\left(z, \omega, \omega^{\prime} \omega-\omega^{\prime}\right)= \\
& \quad \frac{1}{M_{\alpha}} \int\left(\mu \omega^{2}\right) b \phi_{\alpha i}\left(\boldsymbol{r}_{t}^{\prime}, \omega\right) p\left(r_{t}^{\prime}, z\right): \boldsymbol{u}_{a}\left(r_{t}^{\prime}, z, \omega^{\prime}\right) \\
& \quad \times \phi_{\alpha^{\prime} i}\left(r_{t}^{\prime}, \omega-\omega^{\prime}\right) d^{2} r_{t}^{\prime} \ldots \ldots \ldots \ldots \ldots \cdots(26)
\end{aligned}
$$

位相係数は、

$$
\Delta k_{i j}\left(\omega, \omega^{\prime}, z\right)=\beta_{i}(\omega)-\beta_{j}\left(\omega-\omega^{\prime}\right)-\beta_{a}\left(\omega^{\prime}, z\right)
$$

もし、多重周波数の相互作用の場合、的についての積分作 用子を $H=\int d \omega^{\prime}$ とすれば、式 (25) より次の結合方程式 が得られる。

$$
\begin{aligned}
& \frac{d a}{d z}=H A a, \quad a=\left(\begin{array}{c}
a_{1} \\
\vdots \\
a_{n}
\end{array}\right), \\
& A_{i j}=\exp \left[j \Delta k_{i j} z\right]\left(-j \varsigma_{i j}\right)
\end{aligned}
$$

不均質結合倸数の行列 $A$ が要素 $c_{i j}\left(\omega, \omega^{\prime}\right)$ の行列として示 されるとき、 $n$ 多重電磁波につき、 $\omega^{\prime}=\omega^{(1)}, \omega^{(2)} \cdots \omega^{(n)}$ として、第 $i, j$ 番目の電磁波に関し、モード結合の主な第 0 次、第 1 次モード振偪が $b_{0}^{(i)} 、 b_{1}^{(i)}$ 、さらに、他の不均質 搷動による高次の派生第 S 次モードの振幅を $b_{s}^{(i, j)}$ とすれ ば、結合方程式は、 $i, j=1,2, \cdots n$ として、

$$
\begin{aligned}
& \frac{d b_{0}^{(i)}}{d z}=-j \beta_{0}^{(i)} b_{0}^{(i)}-j c_{01}^{(i)} b_{1}^{(i)}-j \sum_{s} c_{0 s}^{(i, j)} b_{s}^{(i, j)} \\
& \frac{d b_{1}^{(i)}}{d z}=-j \beta_{1}^{(i)} b_{1}^{(i)}-j c_{10}^{(i)} b_{0}^{(i)}-j \sum_{s} c_{1 s}^{(i, j)} b_{s}^{(i, j)} \\
& \frac{d b_{s}^{(i, j)}}{d z}=-j c_{0 s}^{(i, j)} b_{0}^{(i)}-j c_{1 s}^{(i, j)} b_{1}^{(i)}-j \beta_{s}^{(i, j)} b_{s}^{(i, j)}
\end{aligned}
$$

摄動論により、光能動性効果による $c_{1 s}^{(i, j)}(z) 、 c_{0 s}^{(i, j)}(z)$ に 関した主たるモード振幅は、 $b_{s}^{(i, j)}=0$ のときの $b_{0}^{(i)} 、 b_{1}^{(i)}$ は 振幅 $b_{0}^{(i),(0)}, b_{1}^{(i),(0)}$ になり、

$$
\begin{aligned}
& b_{s}^{(i, j)}(z)=\exp \left[-j \beta_{s}^{(i, j)} z\right] \\
& \int_{0}^{z}\left(-j c_{0 s}^{(i, j)} b_{0}^{(i),(0)}-j c_{1 s}^{(i, j)} b_{1}^{(i),(0)}\right) \exp \left[j \beta_{s}^{(i, j)} z\right] d z \\
& b_{\left(\begin{array}{l}
0 \\
1
\end{array}\right)}^{(i)}(z)=\exp \left[-j \beta_{\left(\begin{array}{l}
(0) \\
1
\end{array}\right)}^{(i)} z\right]\left(\left(\begin{array}{l}
1 \\
0
\end{array}\right)+\int_{0}^{z}\left(-j c_{\left(\begin{array}{c}
01 \\
10
\end{array}\right)}^{(i)} b_{\left(\begin{array}{l}
1 \\
0
\end{array}\right)}^{(i),(0)}\right.\right. \\
& \left.-j \sum_{s} c_{\left(\begin{array}{c}
(i, j) \\
(1)
\end{array}\right)}^{(i, j)}\right) \exp \left[j \beta_{\left(\begin{array}{c}
(i) \\
(1)
\end{array}\right)}^{(i, j)} d z\right)
\end{aligned}
$$




$$
\left|b_{0}^{(i)}\right|^{2}=\frac{|c|^{2}}{|c|^{2}+|\Delta \beta|^{2}} \sin ^{2}\left(\sqrt{|c|^{2}+|\Delta \beta|^{2}} z\right)
$$

$$
\text { となる。 }
$$

$$
\text { ここで、 } \Delta \beta=\beta_{\text {ele }}-\Delta \beta_{\text {opt }} 、 \Delta \beta_{\text {opt }}=\left|\beta_{0}^{(i)}-\beta_{1}^{(i)}\right| \text { 、 }
$$

$\beta_{\text {ele }}=\beta_{S A W}, \beta_{M S S W}$ 。

また、このときのモード振幅による分光フィルタ特性は、 SAW およびMSSW のとき、たとえば図 5 のように示され る。1,11)

式 (30) において、式 (6)の 2 つの電気采無線波入力の 相関スペクトル $\hat{R}=\hat{g}_{1} \hat{g}_{2}$ は、非線形項 $c_{01}^{(i, j)} c_{01}^{(i, j)}$ あるいは $c_{10}^{(i, j)} c_{10}^{(i, j)}$ により次式の成分によって与えられる。

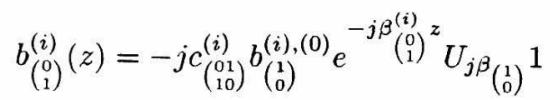

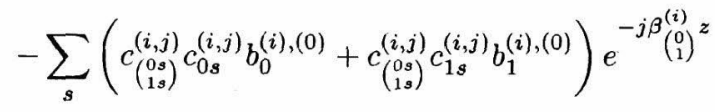

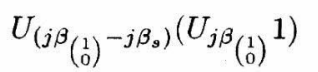

$$
\begin{aligned}
& U_{j f} g=\int_{0}^{z} g e^{j f z} d z
\end{aligned}
$$

したがって、式(15)、(23)を用いて、式(32)より、相関 関数 $R(t)$ は光出力として

$$
\boldsymbol{E}_{(i)}(\boldsymbol{r}, t)=\frac{1}{2 \pi} \int_{0}^{\infty} b_{\substack{0 \\
\left(\begin{array}{l}
0 \\
1
\end{array}\right)}}^{(i)}(z) \phi(i)\left(\boldsymbol{r}_{t}, \omega\right) e^{j \omega t} d \omega
$$

の成分として得られる。また、遅延時間は相関関数のピー ク值を与える時間変数值により与えられる。

\section{5. まと め}

高速移動無線通信における遅延雑音フィルタリングに必 要な実時間高速信号処理には、SAW あるいは MSSW を用 いた A-O、M-O 効果を利用した光機能性導波路素子が有 効である。マイクロ波、ミリ波を搬送波とする高速移動無 線の電気系入力を印加した光機能性導波路における光波と 多重電磁波の相互作用についての基碇理論を示した。この 理論に基づいて、さらに、移動無線システムの最適設計に 必要な設計理論を今後示す予定である。

(平成 9 年 4 月 28 日受付, 同 9 年 9 月 3 日再受付)

\section{文 献}

(1) T.Kondo,Y.Miyazaki and Y.Akao : "Optical Tunable Switched Directional Couplers Consisting of Two Thin-Film Waveguides Using Surface Acoustic
Waves",Jpn. J. Appl. Phys.17,7 ,1231 1243 (1978)

（2）宮崎：超音波スペクトロスコピー 応用編（生嶋、御子 柴)，72 101，培風館 (1990)

(3) C.S.Tsai : Guided-Wave Acousto-Optics, SpringerVerlag(1990).

(4) A.D.Fisher : "Optical Signal Processing with Magnetostatic Waves",Circuits, System and Signal Processing, 4,1-2, 265 284 (1985)

(5) N.Goto and Y.Miyazaki : "Integrated Optical Multi/Demultiplexer Using Acoustooptic Effect for Multiwavelength Optical Communications", IEEE J. Sel. Areas Commun.,8,6 , 1160 1168 (1990)

(6) N.Goto Y.Kanayama amd Y.Miyazaki : "Integrated Optic Matrix-Vector Multiplier Using Multifrequency Acoustooptic Bragg Diffraction",Appl. Opt.,30,5 ,523 530 (1991)

(7) Y.Miyazaki: "Propagation Properties of Optical Signal Waves in Perturbed Dielectric Waveguides by Conformal Mapping Technique", Topical Meeting on Integrated Optics, OSA, IEEE, Las Vegas, WA2(1972)

（8）宮崎：「LD 励起用屈折率分布型導波路結合素子の電磁 界特性」、電気学会、電磁界理論研資 EMT-91-160 (1991)

(9) Y.Miyazaki:"Partially Coherent Optical Waves in Random Gradient Fibers", Opt. and Quantum Electron.,9,153 165 (1977)

(10) R.Bandari and Y.Miyazaki, "Optical Mode Conversion Induced by Magnetostatic Surface Wave in Three-Dimensional Waveguides",Trans. IECE Japan,E67, 9, 502 508 (1984)

(11) K.Hasegawa and Y.Miyazaki, "Characteristics of Integrated Optical Devices Using Magnetostatic Surface Waves",Jpn. J. Appl. Phys., 29,Suppl.29-1, $270 \sim 273$ (1990)

(12) K.Kikuchi and Y.Miyazaki: "Optical Mode Conversion by Magnetostatic Surface Waves in Optical Waveguide-Type Devices Using Cerium- and Bismuth-Doped Garnet Crystalline Films", Jpn. J. Appl. Phys., 34, 5B, Part 1, 2920 2924 (1995)

宮 崎 保光（正員） 1941 年 2 月 4 日生. 1963 年 3 月

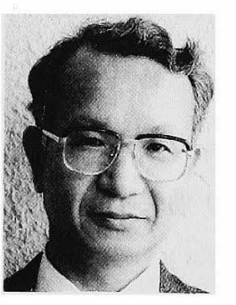
名古屋大学工学部電子工学科卒. 1968 年 3 月 名古屋大学大学院工学研究科電子工学尃攻博 士課程修了. 工学博士. 1972 年同大学工学部 電気工学科講師, 1976 年同大学助教授. 1981 年豊橋技術科学大学工学部情報工学系教授, 現在に至る.この間, 1973 年〜1975 年西ド イツ・ブラウンシュバイク工科大学高周波研 究所に客員として出張, 1996 年ベルリン工科大学の客員教授. 主として,ミリ波導波路, 光ファイバ, 光集積回路, 電磁波の 散乱・回折, EMC, 生体電磁工学の研究に従事. 1970 年米沢 賞受賞. 著書「応用べクトル解析」。応用物理学会, 電子情報通 信学会, IEEE 会員. 